Article

\title{
"Here, There, in between, beyond...": Identity Negotiation and Sense of Belonging among Southern Europeans in the UK and Germany
}

\author{
Fabio Quassoli ${ }^{1, *}$ and Iraklis Dimitriadis ${ }^{2}$ \\ ${ }^{1}$ Department of Sociology and Social Research, University of Milano-Bicocca, 20126 Milan, Italy; \\ E-Mail: fabio.quassoli@unimib.it \\ 2 Department of Social and Political Sciences, University of Milan, 20122 Milan, Italy; E-Mail: iraklis.dimitriadis@unimi.it \\ * Corresponding author
}

Submitted: 31 July 2019 | Accepted: 2 October 2019 | Published: 7 November 2019

\begin{abstract}
Whilst most of the research on intra-EU mobility has mainly focused on the reasons behind young Southern Europeans leaving their home countries, and secondly on their experiences within the new context, little is known about their sense of belonging and identities. This article aims to fill this gap by exploring Italian and Spanish migrants' social identity repositioning and the cultural change characterising their existential trajectories. Drawing on 69 semi-structured interviews with Italians and Spaniards living in London and Berlin, this article shows that the sense of belonging to one or more political communities and boundary work are related to individual experiences and can change due to structural eventualities such as the Brexit referendum. While identification with the host society is rare, attachment to the home country is quite common as a result of people's everyday experiences. Cultural changes and European/cosmopolitan identification are linked to exposure to new environments and interaction with new cultures, mostly concerning those with previous mobility experience, as well as to a sentiment of non-acceptance in the UK. However, such categories are not rigid, but many times self-identification and attachments are rather blurred also due to the uncertainty around the duration of the mobility project. This makes individual factors (gender, age, family status, employment, education) that are often considered as determinants of identification patterns all but relevant.
\end{abstract}

\section{Keywords}

belonging; identity; Italians; migration; Southern Europe; Spaniards

Issue

This article is part of the issue "The Lived Experiences of Migration: Individual Strategies, Institutional Settings and Destination Effects in the European Mobility Process" edited by Neli Demireva (University of Essex, UK) and Fabio Quassoli (University of Milano-Bicocca, Italy).

(C) 2019 by the authors; licensee Cogitatio (Lisbon, Portugal). This article is licensed under a Creative Commons Attribution 4.0 International License (CC BY).

\section{Introduction}

The study of mobility within the European Union has been gaining momentum since the year 2000 (Sacchetto, Vianello, \& Andrijasevic, 2016). Initially, most investigations focused on people coming from Eastern European countries. However, once the consequences of the 2008 financial crisis started to spread throughout Europe, the focus has shifted to the new migratory flows from Southern Europe, in particular from Italy, Spain and Greece. As far as the latter wave of studies is con- cerned, scholars have paid greater attention to the sociodemographic characteristics of new movers and reasons behind their decision to move towards Northern European countries (Caneva, 2016; King, Lulle, Conti, \& Mueller, 2016; Recchi, Barone, \& Assirelli, 2016; Triandafyllidou \& Gropas, 2014). Up until now, very few works have been devoted to questions relating to the reconfiguration of both social identity and belonging, the process of adaptation to new socio-cultural environments and transnational ties accompanying the existential trajectories of intra-European mobile people. 
Moreover, they mainly focused on people coming from Eastern-European countries (Goulahsen, 2017; Kennedy, 2008; Ranta \& Nancheva, 2019; Ryan, 2018).

Our article firstly aims to explore identity redefinition processes among Italian and Spanish people as they settle in another EU country. Drawing on 69 semistructured interviews with Italians and Spaniards living in London and Berlin, we try to illustrate both identity repositioning and the cultural change characterising their existential trajectories. ${ }^{1}$ We also analyse their sense of belonging to one or more political communities (Anthias, 2006; Antonsich, 2010), as well as the (inter)cultural horizon within which they make sense of everyday experiences. Lastly, we aim to highlight how a close link between territory and culture may not be so important and how cultural references may be of a composite, opportunistic, negotiated and, above all, deterritorialised nature (Glick Schiller, 2003).

\section{Identity, Belonging and Migration}

In our article, we use the term 'identity' to refer to the social dimension of the concept itself: a feeling of belonging to specific social categories (Stryker, 2008). In this sense, social identity is not unique, but multiple. Each individual, in fact, identifies him/herself in multiple culturally defined categories, each of which incorporate a precise cultural horizon of reference: age, gender, lifestyle, football or religious faith, nationality, etc. (Burke \& Stets, 2009). Furthermore, these identifications are activated in relation to the type of solicitations that come from the variety of contexts of daily experience: If at the stadium we tend to define ourselves in terms of football faith, during a multicultural public event, a definition of both oneself and others in terms of nationality/ethnicity could be more likely and salient. Moving to a new country makes the reference to a cultural horizon defined in terms of nationality/ethnicity more relevant whether we insist on stressing its importance or we try to downplay it. Asserting a social identity implies that people draw a symbolic distinction between their own category of belonging and the one to which, in their opinion, others belong (Owens, Robinson, \& Smith-Lovin, 2010). Social identity, as we will see later, is usually asserted in essentialised terms: an individual recognises oneself as a certain type of person and automatically alters somebody else in opposition (Baumann, 1999). However, it has also a constitutively positional nature: The way we draw a symbolic line that defines in-group and out-group borders, in fact, is always contingent and linked to each particular context of interaction (Hall, 1990).
As previously mentioned, social scientists have paid very little attention to identity transformation processes among intra-EU people on the move thus far. Exceptions include recent survey-based research (Rother \& Nebe, 2009; van Mol, 2013) investigating mainly the presence and relevance of a European identity among European migrants in various EU countries. This research commonly shows that mobile Europeans form a stronger European identity compared to non-mobile ones, and that there are significant differences between countries regarding the degree of identification with Europe. For instance, van Mol (2013) argues that people coming from Austria, Belgium, Italy and Poland seem to be more pro-European, whereas their British and Norwegian counterparts tend to share a certain Euroscepticism. Furthermore, attachment to European identity is reinforced over time and is stronger for those having experienced Erasmus mobility (Cocorullo \& Pisacane, 2017).

On the other hand, qualitative studies on intraEuropean mobility provide some insight into subjective identification by studying how people adapt and settle into their host society, as well as their socialisation patterns and transnational ties (Goulahsen, 2017; Kennedy, 2008; Ryan, 2018). For example, empirical evidence from interviews with high-skilled workers in the UK (Goulahsen, 2017; Kennedy, 2008) showed that migratory experiences may transform or destabilise a sense of belonging to specific national cultures or help create new identities. Kennedy (2008) stated that attachment to 'original' national identities weakens over time and frequent interactions with other cultures within the host society result in a blurred sense of belonging and cultural attachment to a specific country. In the same way, Goulahsen (2017, p. 158) argued that identities "are a ground of negotiation, contestation, deconstruction and reconstruction." The author proposes the concept of "transculturality," which is migrant identification with different (hybrid) cultures (home and/or host society or cosmopolitan identity), the acquisition of new traits and/or loss of original cultural traits, as well as strategic cultural identity rearrangement.

Shifts in self-identification are also confirmed in a recent mixed-method study on European nationals in the UK (Ranta \& Nancheva, 2019). Although four distinct identification categories have emerged: disidentification with country of origin; identities detached from bounded belongings; identification with both country of origin and destination; and attachment to the country of origin. It is argued that parameters determining these patterns can shift, mainly due to events that can unsettle foreigners' status and rights, such as the Brexit referendum result in

\footnotetext{
${ }^{1}$ This article draws on data from a Horizon 2020-funded research project on intra-EU mobility that aimed to explore migrants' lived experiences (Growth, Equal Opportunities, Migration and Markets [GEMM] project). Between November 2016 and June 2017, 160 in-depth interviews were carried out with Italian and Spanish migrants in the UK and Germany and with Bulgarian and Romanian migrants in the UK, Germany, Italy and Spain. The interviewed migrants were equally divided between men and women. One third were low-skilled working (or willing to work) in construction, domestic care, retail and services; two thirds were high-skilled working in the sectors of finance, ICT, construction and health. For more details, see the research project website (http://gemm2020.eu). The vast majority of our interviewees migrated during the 2010s (only nine out of 69 migrated between 2002 and 2009). Our analysis focusses almost only on Italian and Spanish interviewees, although on some specific issues that will be dealt with in the following paragraphs, we also draw on the other two case-studies.
} 
2016 (Gumbrell-McCormick \& Hyman, 2017; Marino \& D’Onofrio, 2017).

Typically, more recent studies show that the sense of belonging of intra-EU mobile persons in the UK has been disrupted by the uncertainty surrounding the UK withdrawal procedure, and the feeling of exclusion from British society (Botterill \& Hancock, 2019; McCarthy, 2019; Ranta \& Nancheva, 2019). Their possible attachment to the UK, developed in previous years, has been challenged. This often generates uncertainty about the future or thoughts about a return to the country of origin (McCarthy, 2019); yet, the economic situation and labour market conditions in Spain and Italy are often perceived as deterrents (Bygnes, 2017; Dimitriadis, Fullin, \& FischerSouan, 2019). At the same time, the Brexit referendum result could trigger a new sense of 'Europeanness' (Ranta \& Nancheva, 2019), or the rediscovering of a sense of belonging to the $\mathrm{EU}$ in order to mitigate any fears linked to the future of EU residents in the UK.

\section{A Typology of 'Belonging' and Identities}

Now, let us see how interviewees living in the UK and Germany define their identity and express feelings of attachment to different territorial and cultural entities. Our focus is on the country of origin, host society (at a localcity and/or national-country level), as well as at a supranational EU level.

Overall, we found three patterns of cultural identification/sense of belonging that were very similar to those proposed by Goulahsen (2017): firstly, a renewed and strengthened identification with the country of origin; secondly, an assimilation of the civic culture of the country of immigration-subjectively experienced also in terms of "acculturation" (Gudykunst \& Kim, 2003) and similar to the "disidentification" process highlighted by King et al. (2016); thirdly, a cosmopolitan attitude that could be related either to a transnational dimension (the feeling of being European) or the multicultural landscape characterising everyday experiences in global cities such as London and Berlin.

Naturally, we are well aware that identity formation processes are dynamic, as they are subject to changes in the host society and depend on personal experience. However, we believe that these three patterns of identity change are ideal-types, necessary to shed light on different types of belonging to (and relationships with) the home-host society, as well as to/with the supranational dimension. Both can change over time, outlining a sort of standard path of identity reconfiguration, and be tactically enacted in different everyday life situations, enabling people to position themselves towards those who are recognised as their interlocutors.

\section{1. "German? Never!"}

A common subjective self-identification pattern among respondents is a cultural attachment to their country of origin. The majority of respondents in all four case studies expressed, first and foremost, their sense of rootedness to the cultural tradition of their home country. Expressions such as "I still feel Spanish" or "I will never stop feeling Italian" were common in their narratives. Of particular interest is the fact that a strong national cultural identity does not seem to correlate with the sociodemographic characteristics of informants, that is their age, level of education, profession, length of stay, citizenship status and gender.

For example, some of our Italian respondents seek to identify more with the cultural traditions of Italy ('Italianity'), rediscovered via contacts with the new cultural context/model. In particular, they may reassess the identity of their home country, dispelling common myths about the superiority and efficiency of other countries and highlighting the positive values of the cultural space they previously underestimated. An Italian architect living in London told us:

I feel Italian, and now I appreciate many things I've always had before. I appreciate most things that before, having them every day, I didn't; you realise how important they are. (Italian, architect in London, female)

We find similar evaluations in our Spanish case studies:

I feel very Spanish in general....I simply feel Spanish because I've lived in so many places in Spain that I can't say I'm from Málaga or Cáceres or...and here, in Germany, I feel Spanish....Maybe more Spanish than before, yes...I'm more conscious of the cultural differences [between Germany and Spain], in general, and of the different characters, which somehow makes me prefer [the Spanish character and culture]. (Spaniard, physician in Berlin, female)

Similarly, another Italian architect in London, after saying that Italians tend to idealise people from other nations because their economies are more efficient, states that after many years abroad (China, Netherlands and UK) he now appreciates Italian cultural characteristics, implying that all cultures have both negative and positive traits. Taking into account the example of these high-skilled interviewees as well as those of many others of high education level working in prestigious work sectors (e.g., finance, engineering, health) on the one hand, and other examples of low-skilled informants on the other, we suggest that a renewed or strengthened identification with Italy or Spain has little to do with education level or type of work, which is in contrast to what literature suggests:

As I move around, I really appreciate the "Italian" in me. [Italians tend to] idealise others, but then one realises that with the civility of the Dutch comes "dullness" and with the kindness and good manners of the English come "fake" and unanimated conversations. (Italian, architect in London, male) 
Strong identification with Italian and Spanish culture is often considered to be in contrast with the local cultural model of the host society. The following quotes are suggestive of static self-images-as if culture works as a type of DNA-and are steeped in cultural stereotypes. One strategy that individuals adopt when under external pressure to assimilate a "different" culture may be that of reaffirming their "identity" and "culture" of origin. The following are excerpts from our Italian interviews:

[My identity] has absolutely not changed....I mean it has not changed so much in me.... In fact, I feel maybe even more Italian, since when I arrived here, there was no identity. Now that I'm here, I make comparisons all the time.....In short, I feel more Italian now (Italian, physician in London, female)

German never! However, not because I hate the Germans, but possibly because I still see them as very different from me. I see myself as Italian (Italian, nurse in Hamburg, male)

Similarly, some Spaniards strongly identified with the cultural traits of Spain, especially in the case of those living in Germany. They express their attachment in terms of a desire to transmit Spanish cultural values to their children, as well as the belief that Spanish culture is incompatible with the German one. A Spanish nurse clearly displays this tendency:

I would prefer to return to Spain, especially for the future of my [hypothetical] child, thinking of him. He would be better off there. At least he would be in my culture, dammit! I would like him to become integrated into Spanish culture, whereas, if he is here [in Berlin], he will learn German culture, whether we like it or not. Obviously, our culture would be in the home, but his friends, other children and classmates, his day-to-day routine would be German. And even though you can try and maintain your culture in a foreign country, it is very, very difficult to transmit. (Spaniard, nurse in Berlin, male)

An investment analyst from Barcelona also expresses similar concerns about raising children in Germany despite his extensive international educational and professional experience:

The values I would like to transmit are very common in my family and circle of friends [in Spain]. It would be far easier for me to raise my children according to those values if they could see them in the people that surround them [by returning to Spain]....For example, my grandmother lived with us for a long period of time [in Spain]. That would be inconceivable for a German. (Spaniard, financial services consultant in Berlin, male)
Even though having a family might imply a deeper attachment to the culture of the country of origin, other research suggested that feeling at home in the destination country is more common among those who have long-term migration projects, that is those with families (McCarthy, 2019). As we argue below though, those in families equally fall into other identification categories both in the UK and Germany, thus making the link between family situation and sense of belonging all but clear.

The cultural distance between national identity and the cultural environment in which they live strongly influences the interviewee's attitude towards acquiring dual nationality. In fact, they would not be willing to apply for British or German citizenship because they do not feel culturally-and do not want to be perceived-as British or German. They feel that dual nationality would make them definitely German or British, and therefore would not be happy with such an evolution of their cultural identity and traits. A young Italian in Berlin, who does not intend to apply for naturalisation, links the acquisition of citizenship with his feelings as regards the cultural traits of German people: "I feel far from the Germans [Germans' cultural traits], too far. And I don't even want to get too close" (Italian, nurse in Berlin, male)

The idea that citizenship is intrinsically linked to national identity, especially in the absence of barriers to free movement, has been highlighted by several respondents. In contrast to other studies suggesting that nonEU residents may cope with the ban on dual citizenship by downplaying the effect of new citizenship on their identity (Yanasmayan, 2015), some of our interviewees place a high symbolic value on their own nationality (which they often equate with identity). They also tend to view another citizenship, and therefore, another identity, as (symbolically) incompatible with their self-understanding:

Basically, I'm Italian. I'm not interested at all (Italian, cook in London, male)

I don't think so [apply for German citizenship]. I would like to return to Italy, but actually, I don't feel German. I've remained very much attached to Italy (Italian, financial services consultant in Berlin, male)

In the case of the UK, being opposed to naturalisation seems also to be an outcome of the referendum on Brexit, thus confirming recent research results (McCarthy, 2019; Ranta \& Nancheva, 2019). Although feeling vulnerable to the changing climate in the UK and worrying about the implications of Brexit for his status (GumbrellMcCormick \& Hyman, 2017; Marino \& D’Onofrio, 2017), a Spanish construction worker mentioned:

If they don't want me here, then I don't [getting British citizenship]. If they don't want me [now], they won't want me with or without [British] citizenship, 
so I'll leave. I don't want to be where I'm not wanted (Spaniard, carpenter in London, male)

\section{2. "Now I Am a Better Person!"}

A second identity pattern regards those informants who tend to internalise the national culture of the host society while developing a more critical view of their society of origin than they had in the past.

Identities are challenged and transformed as individuals become gradually embedded into a new context. In fact, we noticed several instances where interviewees presented themselves as increasingly "detached" from what they perceived as predominant mentalities in their home cultures.

Italians' and Spaniards' acculturation may be interpreted as a desire to share new cultural habits that permit individual growth; or, in other cases, it may be seen as a way of assimilating the typical traits of a cultural model that is considered more civilized and evolved. A 40-year old Italian software designer and a 28-year-old architect echo this sentiment:

I cannot stand certain things about it [Italy] anymore..... In some places, you are looked at from head to toe because you're dressed in a certain way. The myopia of the typical Italian, in the sense of this parochialism.....taly is going nowhere; our mentality is overly defensive. I would like things to work in another way in an evolving world....Yes, because I have met different people, I have seen different things-for better or for worse-I have had many more experiences. The first year I spent here could be compared to having spent ten years in Italy....We are far behind, far less civilized. (Italian, computer scientist in London, male)

I have definitely changed a lot, especially since I started working. It's been two years. When one lives and grows up in [the same] country...your vision of the world is limited. When one lives in the same country, it seems as though you are living in a parallel reality....So, there is a "provincial" mentality, in which people know everything about everyone [around them], but are not interested in what happens [outside]....In my opinion, it [migration] completely changes your way of thinking. (Italian, architect in Berlin, female)

The following quotes from Spanish respondents suggest a strong similarity with Italians who are proud to be distancing themselves from "parochial" societies while becoming integrated into new local and even more "European" environments:

I feel more...solidarity with other immigrants, for example. Before, I had no...I knew nothing about the rest of Europe. We were "confined" to Spain and very often got the sense we were living in a bubble. We see only Spain and we care only about Spain and we don't see anything beyond the borders. I think we need to break that [tendency]. (Spaniard, engineer in London, female)

When I go home [to Barcelona], all of my friends have the same job as before, no one has changed their job...I would say this is a negative...as they complain, all of them moan but they don't change anything. Whereas I....When I [started] moaning about my job at the bar [first job in London], I changed. And now, I'm happy, but if I start moaning again, I can change. In Spain, everyone complains but no one does anything, they always stay the same. (Spaniard, receptionist in London, male)

Although participants with different family status, duration of migration project and working sector might be equally disidentified with Italy or Spain, it seems that those having experienced poor work conditions in the home-country labour market or unemployment during the economic crisis tended to distance themselves from some cultural traits (Dimitriadis et al., 2019). In the following excerpt, an Italian café manager who moved to London with his girlfriend due to poor employment opportunities in Italy criticised Italian clients' behaviour. In addition, achieving a good command of the language becomes both a way of feeling at ease in everyday situations and a symbol of positive change in the way they think and express their own ideas:

I work in a cafeteria, which has an Italian name, and many Italians come in here...I can tell you that the average Italian customer...apart from the fact that they cannot speak English; they absolutely cannot say a word. You speak English and they answer in Italian! Not knowing that you are Italian, but they pretend that you understand their language and if you don't understand it, they raise their voices or try to punctuate the words. (Italian, bar tender/manager in London, male)

The passages above illustrate how many of our Southern European respondents display a great sense of pride in what they have achieved within the new context while providing a negative view of "backward" Mediterranean societies. Moreover, they express a rather pessimistic vision of their countries' future prospects. These subjects perceive and describe themselves in positive and idealised terms, resilient people able to overcome deeply internalised cultural habits, whereas those who "stayed behind" are described in reified terms, "cultural-dopes," unable to free themselves from the bonds of their national culture.

"Acculturation" seems linked to a positive attitude towards naturalisation as a British or German citizen. These interviewees not only consider new citizenship as the natural result of a long road to socio-economic integration within the host society but also, in line with a ne- 
oliberal concept of citizenship, something that has to be deserved and that they definitely deserve (Monforte, Bassel, \& Khan, 2019):

I see it [naturalisation] as one more thing. I wouldn't say it should be so [laughs], but at least it would be consistent with the pathway undertaken in eight years. (Italian, computer scientist in Berlin, male)

Lastly, and in line with the concept that citizenship is a privilege kings and governments bestow to an increasingly larger proportion of the population living on a territory, these interviewees see British or German citizenship as a status symbol. As an Italian IT entrepreneur in London clearly states: "I would be better represented if I had a British passport rather than an Italian one" (Italian, computer scientist in London, male).

\subsection{Uprooted and Happy}

The third type of identity pattern we encountered in this study was of a cosmopolitan and European nature. Attitudes held by individuals who simultaneously evaluate the national cultural references of their country of origin while adapting easily to new lifestyles. These people not only embrace new cultural environments but also tend to define their new identities as being between two or three "worlds": their country of origin, their destination and a supranational European and/or cosmopolitan identity. Before studying the cosmopolitan and European identities of our two national groups, it is worth highlighting the relevance of our interviewees' previous migratory experiences as well as the duration of EU membership of those countries of origin in question. Typically, individuals that have more experience in mobility (mainly through student exchange programmes) and a longer history of EU membership are more likely to identify with this category (Cocorullo \& Pisacane, 2017).

New experiences have stimulated in many Italians and Spaniards a sense of belonging to a wider cultural context accompanied by a cosmopolitan attitude towards national cultural models, marked by a constant openness to new experiences and a positive attitude to being uprooted. Moreover, cosmopolitan values are linked to previous mobility experiences through Erasmus or internship programmes within Europe (Cocorullo \& Pisacane, 2017) and coincide with a greater European identity. It could also be argued that this pattern was more common among high-skilled workers:

I am a real pro-European. I was bewildered by the Brexit vote; I was seriously thinking of leaving a country that does not want you, I feel very European because I grew up in the Erasmus culture, Europe etc. Then, having lived the university environment with young people of various nationalities, in my opinion multiculturalism is of great value. (Italian, financial services consultant in London, male)
[As a result of an Erasmus exchange and Masters programme in] Maastricht and Denmark...I've ended up feeling more European and also more removed from the "standard" of what is considered Spanish culture...I didn't have many expectations when I came to Berlin. The only minimum expectation was that in terms of job experience and the experience of living abroad. However, I have found much more than that. I have found friends, I have found...I don't know, values that I didn't have before, I have developed a much broader view of the world. (Spaniard, computer scientist in Berlin, male)

Deeper identification with the European identity was also a result of the Brexit vote (Ranta \& Nancheva, 2019):

After Brexit, I feel more European. It was an incredible disappointment. I respect British people's decision, however, to be honest, in my opinion, they are in the wrong way. I do not know what will happen, if they treat us as commodities, and make our life difficult here. I think we have an opportunity elsewhere: in our country or other countries, but they will pass a very difficult time. (Italian, nurse in London, male)

It is interesting how for some individuals, cosmopoli$\tan$ values seem to have existed prior to the international experience:

I've never felt Spanish, I mean...neither Valencian, nor Catalan, none of those. I have always considered myself a citizen of the universe.... like to move around. (Spaniard, electrician in Berlin, male)

All respondents view multiple identities as highly compatible, endorsing the idea of fluid and hybrid identities, whether they believed or not that their cosmopolitan values and European identity were the result of migratory/previous international experiences. When asked if he felt somewhat less Spanish than before as a result of living in London, this nurse replied:

The point of living abroad is to "add" new things, not to lose them. I don't feel less Spanish. Now, I feel more things. I feel more English, more European. (Spaniard, nurse in London, male)

A telecommunications engineer who moved to a small city outside London with her husband and two young daughters echoed this sense of satisfaction, having acquired "multiple" identities as a result of migration:

I definitely feel more European [now]. I feel more like a citizen "of the world," you feel...you still feel Spanish...you're still Spanish but you can now see that your main objective is not living in Spain and being Spanish....So, I feel more international, in general. Not exactly more European, but more interna- 
tional...that's how I feel. (Spaniard, customer service representative in London, female)

Identifying with two or more cultures, a "mix or hybrid of cultures and identities developed by migrants" (Goulahsen, 2017, p. 162), involves the notion of transculturality. According to Benessaieh (2010, p. 21) transcultural subjects have learnt multiple cultural habits, and, as a result, their identity seems multiple and complex, rather than static. In the words of an Italian participant:

To tell you the truth, I don't think I've ever had roots...I'd like to feel a little English. I bought the book to apply for citizenship many years ago and I've not finished it yet, I don't know whether, on an unconscious level, I want to finish it or not. I definitely feel Italian, I feel part of my community and I'd like to give back what I was given in my country. Perhaps I'd like to live in a country that is situated between the two [Italy and UK]. (Italian, midwife in Oxford, female)

\subsection{Urban Cosmopolitanism}

As Coletto and Fullin (2019) highlight, social imageries concerning places of destination deeply influence the way people moving from Italy or Spain to London and Berlin think about themselves and define their intraEuropean mobility (Pessar \& Mahler, 2002). The two cities are perceived by our informants-by both those who are going to leave and those who already live thereas lively, dynamic, attractive and global. Most of them confirmed it was easy to feel included within urban contexts that are very international and open to integrating foreigners. Moreover, some of them specifically retraced their cosmopolitan attitudes as being shaped or strengthened by the metropolitan/multicultural and globalised contexts where they live rather than drawing on the general experience of mobility and migration. In these cases, both London and Berlin are seen as different from the national context in which they are located, since they are much more European, globalised and multicultural:

Living in London puts you in touch with the world. For example, I work on a team consisting of an Italian, myself, a Spaniard, a Frenchman, a girl from Hong Kong, my American boss and a Lebanese. There are four English people and one German. (Italian, financial services consultant in London, male)

What I really love about London at this moment in time, and the reason why I don't want to go back to Spain, is because my best friend is German and my other best friend is French and half Russian....Our group of friends includes a guy from Zimbabwe, a Chinese girl, a Brazilian girl....My male friends are Italian, Irish, British....I mean...it's super international. That is what I was looking for when I came here, that is what I've achieved: to be able to access such diversity which is so enriching, both professionally and personally. (Spaniard, financial services consultant in London, female)

Several informants who live in Berlin and London say these two capitals are very different from other parts of Germany or the UK. This distinction often regards the international and cosmopolitan nature of these cities, resulting in opportunities to socialise with new people and live without being judged by anyone:

Berliner society is not the same as German society. Berlin is a very international city...it's hard to find "real" Berliners.... It's an international environment, with people who come and go. (Italian, tourist guide in Berlin, female)

[When asked if he ever felt like a Berliner] Yes. Not like a German, but I sometimes feel like a Berliner.... feel very comfortable in Berlin. (Spaniard, computer scientist in Berlin, male)

Looking comparatively at our participants living in Berlin and London, it could be argued that, even though interaction with German or British people was not common, many Italians and Spaniards in Berlin did not speak German at all, thus limiting the possibility to socialise with locals. This has been the case either for high-skilled people working in international environments where English was the spoken language or for low-skilled workers employed by Italian or Spanish employers. When reflecting on German culture traits, some of these participants tended to reproduce stereotypes cultivated in the home country.

\section{Further Considerations}

Before outlining some conclusive remarks, we would like to point out four additional aspects.

Firstly, looking comparatively on the analysis of the four case-studies (Italy, Spain, Romania, and Bulgaria) from the GEMM project, one can underline the importance of historical, political and socio-economic contexts in shaping mobile people identities. As far as an attachment to home country is concerned, we can trace a clear distinction between Eastern and Southern Europeans. Whereas Italians and Spaniards seem to 'rediscover' certain traits of their home society that they were less aware of previous to migration, encouraging them to reaffirm their attachment to lifestyles and values in the country of origin they perceive as absent from the country of residence, the attachment of Bulgarians and Romanians to their home country seems to be more shaped by problematic reception in the receiving society (see also Donatiello, 2013; Fox, Moroşanu, \& Szilassy, 2012).

Also in this case of the second type we identified, it is important to point out a fundamental difference with 
respect to the interviewees from Eastern Europe. Indeed, the latter seems to undertake a path of cultural assimilation and rejection of the culture of origin because they want to strongly dissociate themselves from negative images of Eastern Europeans residing abroad. They felt rejection and alienation on the part the host society either because they worked in positions that did not reflect their qualifications (de-skilling) or because they encountered obstacles in socialising with locals. Furthermore, they want to avoid being stigmatised as 'lazy' or 'criminals' (Donatiello, 2013), and they even rejected the idea that they should be considered as 'migrants,' a category which they associated with poor unsuccessful compatriots abroad.

In addition, cosmopolitan attitudes were mainly presented among highly-skilled Bulgarian interviewees, who tended to associate them with their sense of a European identity. Attachment to the European sphere was common for Bulgarians who recognised the benefits of Bulgaria's membership in the EU, such as the right to free mobility and access to better education opportunities. Bulgarian cosmopolites may take part in local life and socialize with people from any nationality. The cosmopolitan and European orientations tended to be most prevalent among those interviewees who were young, coming from big cities, and with higher education.

Secondly, the possibility to easily maintain daily contact with their country of origin and experiential and relational contexts they have left behind thanks to social networks such as WhatsApp, Skype, Facebook, etc., and the low cost of flights, making it possible to return to Italy and Spain practically every time work commitments allow it and thus minimise the difficulty/need to unequivocally define their cultural identity help develop a sense of multiple belonging to the various places in which they have lived, live and will live (perhaps) in a more or less near future and reduce homesickness:

We have a WhatsApp group and we talk every day. I also talk on the phone with my grandmother and parents once every three to four days. Now, practically, I talk almost every day with them, or I read about what they do. (Italian, computer scientist in Berlin, male)

I speak to them mainly on WhatsApp every other day, sometimes on Skype, if we want to see each other. Being able to send one or two photos a day of where you are, what you are doing, if you have cut your hair, the fact that communication does not cost you any effort, does not cost money, keeps a sense of intimacy alive. It's amazing how there is always that feeling of never having left when I actually come home. (Italian, architect in London, male)

Thirdly, it would seem that the two figures-strangers and homecomers-introduced by Alfred Schütz (1944, 1945) have not lost all of their relevance. 'Strangers,' with their trajectory of increasing cultural integration (under- stood as acquisition of social knowledge, interpersonal skills and ontological security as regards their position within the country of immigration), as well as 'returnees,' who have distanced themselves from the cultural model of origin and, above all, lost contact with the changes underway in their country of origin continue to constitute a good interpretation of the cognitive changes that mark the condition and trajectory of our interviewees:

I do not know. It's actually a mixed feeling because I'm not Italian anymore or English. I'm Italian as a spirit, but sometimes I realise that after living here, I'm used to a way of life I would not find in Italy. So it's a bit of a limbo, I feel like I have two lives, two cultures, or actually I don't even have one. (Italian, architect in London, female)

I feel $100 \%$ Italian, but I'm extremely angry with the people of my country, and I don't know if I could live in Italy. So, I'm in a rather special situation, that is, when I return to Italy I'm pleased because it's still my country, but I would not be there for more than ten days, two weeks, because it makes me nervous. The same thing when I arrive in London. I'm happy to be in my house, but I never feel English. In fact, I could have a British passport, but have not yet done so; I've not thought about it yet. (Italian, financial services consultant in London, male)

While acknowledging that these respondents have become different people, having lost a set of culturally defined habits as they have adapted to their new contexts, they provide a strongly stereotyped reading of their cultural backgrounds. They basically claim that a new cultural model cannot really be internalised to the extent that the original one continues to be associated with a number of positive elements that have been abandoned. At the same time, they no longer recognise themselves in the old overall model, as its failings and limits are too evident.

Fourthly, some narratives we collected highlight the fundamentally positional nature of identity (Hall, Held, Hubert, \& Thompson, 1995). In fact, our interviewees are aware they have acquired a variety of cultural references as well as a cross-cultural communicative (Gudykunst, 2003) competence that enable them to cope with many different everyday life situations, deliberately and consciously staging a multiplicity of dramatis personae (Goffman, 1956). In the words of an Italian informant:

I feel like a foreigner when I go to a pub on Sunday to have lunch because there are only English people in the pubs on Sundays. When I go to work I feel English, when I go to the bank I feel English. When I go to the airport I feel English. When I go shopping I feel Italian. When I go out to dinner I feel Italian. When I come home I feel a bit of both. When I meet someone who comes from Europe, such as France, Spain, I feel English. (Italian, midwife in Oxford, female) 


\section{Conclusion}

This article has explored how Italian and Spanish people in the UK and Germany define their identities and belongings. Our analysis into the subjective and rather intangible outcomes of mobility processes within the EU context have shown that different kinds of boundary work emerge, reflecting changes in personal identity and attachment to different/multiple cultural and territorial spaces through migratory experiences.

First, the renegotiation of cultural belonging cements previous understandings of national or group identification or sets new boundaries as a result of both positive and negative experiences within the host society. Exposure to negative images of 'undesirable' migrants and stigma associated with certain migrant groups can be an incentive to distance oneself from these popular images, rather than actively challenge them. Construction of boundary lines also emerges due to structural changes such as the Brexit vote, in the sense that it reinforces the attachment to Italy and Spain and increases the distance from the host society. In this respect, the economic crisis did not seem relevant.

Second, more positive experiences within the host society may also lead individuals to 'disidentify' with the society of origin, as some describe the migration process as a learning experience leading to levels of personal and cultural development that would have been unattainable or even discouraged in their home countries. Structural changes also determine this pattern as mobile people with negative working experiences in the home country during the economic recession tend to distance themselves from their home countries.

Third, blurring or extending pre-existing boundaries is a somewhat more harmonious identification process, as it often involves understanding multiple spaces of belonging as entirely compatible and commonly expressed by our interviewees as feelings of "being European" and/or "cosmopolitan." This is mainly orientated by previous experiences of European mobility as well as of integration into the cultural and social environments of the host society. Once again, the outcome of the Brexit referendum triggered a deeper attachment to the European identity as a reaction to xenophobic or anti-European attitudes of British people.

Considering how individual characteristics shape identity formation processes and types within the context of EU mobility, we suggest that age, gender, family status, education level, and employment sector do not seem relevant for any of the three identification patterns we discussed. No significant differences emerged from the comparison between Italians and Spaniards, confirming previous research that indicated common mobility patterns among these national groups. Regarding the comparison between the two cities, we argue that the possibility to live and work in Berlin without the necessity of speaking the local language can be a determinant of low attachment to Germany and
German culture and tend to reinforce identification with the home country.

All in all, our findings are more relevant to the dynamic work of setting new boundaries, for instance, between 'movers' and 'stayers,' or between 'desirable' and 'undesirable' migrants (with regards, for instance, to people coming from eastern Europe) as well as blurring previously established ones, e.g., by enriching one's cultural identity to include a more cosmopolitan orientation rather than the question of changing the intensity of belonging (e.g., feeling "more or less" Spanish or German). Future research should adopt a longitudinal qualitative approach to grasp the shifts in intra-EU movers, while comparisons among European people characterised by different mobility patterns would contribute to better understanding around identity process formation within intra-EU countries.

\section{Acknowledgments}

We would like to thank Maricia Fischer-Souan for her contribution to analyse the empirical material and for her useful suggestions and comments on the results presented in the comparative reports in the frame of the GEMM project on Work Package 4.

\section{Conflict of Interests}

The authors declare no conflict of interests.

\section{References}

Anthias, F. (2006). Belongings in a globalising and unequal world: Rethinking translocation. In N. YuvalDavis, K. Kannabiran, \& U. Vieten (Eds.), Situated politics of belonging (pp. 17-31). London: Sage.

Antonsich, M. (2010). Searching for belonging: An analytical framework. Geography Compass, 4(6), 644-659.

Baumann, G. (1999). The multicultural riddle. London and New York, NY: Routledge.

Benessaieh, A. (Ed.). (2010). Transcultural Americas/Amériques transculturelles. Ottawa: Presses de I'Université d'Ottawa.

Botterill, K., \& Hancock, J. (2019). Rescaling belonging in "Brexit Britain": Spatial identities and practices of Polish nationals in Scotland after the U.K. Referendum on European Union membership. Population, Space and Place, 25(1), 1-11. https://doi.org/10.1002/psp.2217

Burke, P. J., \& Stets, J. E. (2009). Identity theory. Oxford: Oxford University Press.

Bygnes, S. (2017). Are they leaving because of the crisis? The sociological significance of anomie as a motivation for migration. Sociology, 51(2), 258-273.

Caneva, E. (2016). Giovani italiani che emigrano: percorsi di vita inediti all'epoca della crisi economica globale [Young Italian emigrants: New life trajectories in the age of global economic crisis]. Mondi Migranti, 3, 79-93. 
Cocorullo, A., \& Pisacane, L. (2017). La mobilità degli studenti Erasmus tra identità europea e nuova emigrazione [Erasmus students' mobility between European identity and new emigration]. Rivista Delle Politiche Sociali, 4, 123-138.

Coletto, D., \& Fullin, G. (2019). Before landing: How do new European emigrants prepare their departure and imagine their destinations? Social Inclusion, 7(4), 320-329.

Dimitriadis, I., Fullin, G., \& Fischer-Souan, M. (2019). Great expectations? Young Southern Europeans emigrating in times of crisis. Mondi Migranti, 3, 137-162.

Donatiello, D. (2013). Farsi una reputazione. Percorsi di integrazione di immigrati romeni [Making a reputation. Integration paths of Romanian migrants]. Rome: Carocci.

Fox, J., Moroşanu, L., \& Szilassy, E. (2012). The racialization of the new European migration to the UK. Sociology, 46(4), 680-695.

Glick Schiller, N. (2003). The centrality of ethnography in the study of transnational migration: Seeing the wetland instead of the swamp. In N. Foner (Ed.), American arrivals: Anthropology engages the new immigration (pp. 99-128). Santa Fe, NM: School of American Research Press.

Goffman, E. (1956). The presentation of self in everyday life. New York, NY: Random House.

Goulahsen, L. (2017). Understanding the complexity of identity and belonging: A case study of French female migrants in Manchester and London. European Journal of Women's Studies, 24(2), 158-173.

Gudykunst, W. B. (2003). Cross-cultural and intercultural communication. Newcastle upon Tyne: Sage.

Gudykunst, W. B., \& Kim, Y. Y. (2003). Communicating with strangers: An approach to intercultural communication. Boston, MA: McGraw-Hill.

Gumbrell-McCormick, R., \& Hyman, R. (2017). What about the workers? The implications of Brexit for British and European labour. Competition \& Change, 21(3), 169-184.

Hall, S. (1990). Cultural identity and diaspora. In J. Rutherford (Ed.), Identity: Community, culture, difference (pp. 222-237). London: Lawrence \& Wishart.

Hall, S., Held, D., Hubert, D., \& Thompson, K. (Eds.). (1995). Modernity: An introduction to modern societies. Hoboken, NJ: Wiley-Blackwell.

Kennedy, P. (2008). The construction of trans-social European networks and the neutralisation of borders: Skilled EU migrants in Manchester-Reconstituting social and national belonging. Space and Polity, 12(1), 119-133.

King, R., Lulle, A., Conti, F., \& Mueller, D. (2016). Eurocity London: A qualitative comparison of graduate migration from Germany, Italy and Latvia. Comparative Migration Studies, 4(1). https://doi.org/10. 1186/s40878-016-0023-1

Marino, S., \& D’Onofrio, G. (2017). La Brexit e l'immigrazione italiana "di nuova generazione" nel Regno Unito [Brexit and Italian immigration of "new generation" in the UK]. Rivista delle Politiche Sociali, 4, 53-76.

McCarthy, H. N. J. (2019). Spanish nationals' future plans in the context of Brexit. Population, Space and Place, 25(1), 1-14. https://doi.org/10.1002/psp.2202

Monforte, P., Bassel, L., \& Khan, K. (2019). Deserving citizenship? Exploring migrants' experiences of the 'citizenship test' process in the United Kingdom. The British Journal of Sociology, 70(1), 24-43.

Owens, T. J., Robinson, D. T., \& Smith-Lovin, L. (2010). Three faces of identity. Annual Review of Sociology, 36, 477-499.

Pessar, P., \& Mahler, S. (2002). Transnational migration: Bringing gender. International Migration Review, 37(3), 812-846.

Ranta, R., \& Nancheva, N. (2019). Unsettled: Brexit and European Union nationals' sense of belonging. Population, Space and Place, 25(1), 1-10. https://doi.org/ 10.1002/psp.2199

Recchi, E., Barone, C., \& Assirelli, G. (2016). Graduate migration out of Italy: Predictors and pay-offs. Notes \& Documents de l'OSC, 2016(3). Retrieved from https:// hal.archives-ouvertes.fr/hal-01399529

Rother, N., \& Nebe, T. M. (2009). More mobile, more European? Free movement and EU identity. In A. Favell \& E. Recchi (Eds.), Pioneers of European integration: Citizenship and mobility in the EU (pp. 120-156). Cheltenham: Edward Elgar.

Ryan, L. (2018). Differentiated embedding: Polish migrants in London negotiating belonging over time. Journal of Ethnic and Migration Studies, 44(2), 233-251.

Sacchetto, D., Vianello, F. A., \& Andrijasevic, R. (2016). Introduzione. Le migrazioni lavorative intra-UE: Modelli, pratiche e traiettorie di mobilità dei cittadini europei [Introduction. Intra-EU labour migration: Patterns, practices and mobility trajectories of European citizens]. Mondi Migranti, 3, 23-31.

Schütz, A. (1944). The stranger. American Journal of Sociology, 49(6), 499-507.

Schütz, A. (1945). The homecomer. American Journal of Sociology, 50(5), 369-376.

Stryker, S. (2008). From mead to a structural symbolic interactionism and beyond. Annual Review of Sociology, 34, 15-31.

Triandafyllidou, A., \& Gropas, R. (2014). "Voting with their feet": Highly skilled emigrants from Southern Europe. American Behavioral Scientist, 58(12), 1614-1633.

van Mol, C. (2013). Intra-European student mobility and European identity: A successful marriage? Population, Space and Place, 19, 209-222.

Yanasmayan, Z. (2015). Citizenship on paper or at heart? A closer look into the dual citizenship debate in Europe. Citizenship Studies, 19(6/7), 785-801. 


\section{About the Authors}

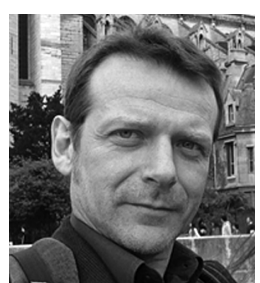

Fabio Quassoli is an Associate Professor at the University of Milano-Bicocca where he teaches Qualitative Research and Intercultural Relations. In recent years, he has worked on immigration control policies, criminalisation of migrants, discrimination, multiculturalism and intercultural communication $\mathrm{He}$ is currently coordinating the Milano-Bicocca team as part of a national project on media, terrorism and security. He is also participating in the WHIG project, an international research network on the governance of large metropolitan areas.

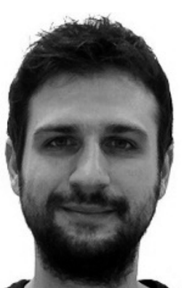

Iraklis Dimitriadis is a Research Fellow at the Department of Social and Political Sciences of the University of Milan. He obtained his PhD in Sociology and Methodology of Social Research from the University of Milan and the University of Torino with the distinction of Doctor Europaeus. His current research focuses on migration governance and asylum crisis within the Horizon 2020 MAGYC project, while in recent years he has developed research on labour migration and integration, informal employment, citizenship, identity, and religion and immigration. 